\title{
Références bibliographiques
}

\section{Catherine Colliot-Thélène}

\section{(2) OpenEdition}

Journals

Édition électronique

URL : http://journals.openedition.org/ries/4179

DOI : 10.4000/ries.4179

ISSN : 2261-4265

\section{Éditeur}

Centre international d'études pédagogiques

\section{Édition imprimée}

Date de publication : 5 mars 1995

Pagination : 149-150

ISSN : 1254-4590

\section{Référence électronique}

Catherine Colliot-Thélène, "Références bibliographiques », Revue internationale d'éducation de Sèvres

[En ligne], 05 | 1995, mis en ligne le 16 mars 2015, consulté le 19 avril 2019. URL : http:// journals.openedition.org/ries/4179; DOI : 10.4000/ries.4179

Ce document a été généré automatiquement le 19 avril 2019.

(c) Tous droits réservés 


\title{
Références bibliographiques
}

\author{
Catherine Colliot-Thélène
}

\section{Sur l'éthique en général}

1 APEL Karl Otto, L'éthique à l'âge de la science, Lille, Presses universitaires de Lille, 1987.

2 Par un auteur proche de Jürgen Habermas, un exposé (dont l'édition allemande date de 1967) sur les transformations de la philosophie contemporaine qui ont abouti à l'idée de «communauté communicationnelle» comme fondement possible d'une morale universelle.

3 HABERMAS Jürgen, Morale et communication: conscience morale et activité communicationnelle, Paris, Éd. du Cerf, 1986. Du même : De l'éthique de la discussion. Paris, Éd. du Cerf, 1992.

4 Deux ouvrages qui, parmi les œuvres de Habermas traduites en français, fournissent les moyens d'accès les plus commodes aux thèses centrales de l'«éthique de la communication ». On pourra consulter aussi sur cet auteur la bibliographie sélective proposée dans RéseauX-CNET, no spécial sur Habermas, 1991.

5 JONAS Hans, Le principe de responsabilité, une éthique pour la civilisation technologique (trad.), Paris, Éd. du Cerf, 1990.

6 Une exploration du problème de la responsabilité dans toutes les dimensions de la vie humaine : famille et éducation, rapports à la technique, organisation de la politique, histoire. Foisonnant.

LARMORE Charles, Moralité et morale (trad.), Paris, Presses universitaires de France, 1994.

8 Illustration d'un courant de la philosophie anglo-saxonne contemporaine qui, à l'encontre du formalisme de l'« éthique de la communication », souligne l'importance des traditions culturelles dans la formation de la conscience morale.

10 Une présentation globale du champ des problèmes et débats actuels. 


\section{Éthique et éducation}

11

12

CANIVEZ Patrice, Éduquer le citoyen, Paris, Hatier, 1990.

FORQUIN Jean-Claude, "L'enfant, l'école et la question de l'éducation morale. Approches théoriques et perspectives de recherches ", Revue française de pédagogie, n 102, 1993, p. 69-106.

KOHLBERG L., LEVINE C, HEWER A., Moral stages: a current formulation and a response to critics, Bâle, Karger, 1985.

LEGRAND Louis, Enseigner la morale aujourd'hui, Paris, PUF, 1991.

MEIRIEU Philippe, Le choix d'éduquer. Éthique et pédagogie, Paris, ESF, 1991. Du même: L'envers du tableau, Paris, ESF, 1993.

PLUNKETT David, Secular and spiritual values. Grounds for hope in education, Londres, Routledge, 1990.

REBOUL Olivier, Les valeurs de l'éducation, Paris, PUF, 1992.

STRAUGHAN Roger, Beliefs, behaviour and education, Londres, Cassell Educ. Ltd, 1989.

WILSON John, A new introduction to moral education, Londres, Cassell Educ. Ltd, 1990.

\section{RÉSUMÉS}

Nous donnons ici une bibliographique sélective: la première partie mentionne quelques ouvrages philosophiques récents susceptibles de donner une idée des grandes lignes de partage de la philosophie éthique contemporaine, la seconde renvoie à des livres ou des articles qui concernent plus précisément la place de l'éthique dans l'école.

\section{AUTEUR}

\section{CATHERINE COLLIOT-THÉLÈNE}

Maître de conférences à l'École normale supérieure de Fontenay-Saint-Cloud, France 